\title{
Role of adaptation level in stimulus intensity dynamism'
}

HARRY G. MURRAY AND DAVID L. KOHFELD ${ }^{2}$

UNIVERSITY OF ILLINOIS

\begin{abstract}
Abstraet
Thirty female college students were first adapted to either a $40 \mathrm{db}$ tone, a $100 \mathrm{db}$ tone, or to silence $(\mathrm{N}=10)$, then given 48 reaction time (RT) trials with randomly ordered presentations of $40,60,80$, and $100 \mathrm{db}$ auditory signals. RT at all levels of signal intensity was fastest for Ss adapted at $40 \mathrm{db}$, slowest for Ss adapted at $100 \mathrm{db}$, and intermediate for Ss adapted to silence. These findings are predicted by Helson's adaptation-level theory but not by Hullian theory.
\end{abstract}

\section{Introduetion}

Many investigators (e.g. Beck, 1963; Chocholle, 1945; Gray, 1965) have reported a positive correlation between conditioned stimulus intensity and conditioned response strength. Hull (1949) termed this relationship "stimulus intensity dynamism." Recent experiments by Grice \& Hunter (1964) have demonstrated that stimulus intensity effects in classical conditioning and simple reaction time are trivial when intensity is a between-Ss variable, but substantially greater in absolute terms when a within-Ss design is employed. Apparently some sort of perceptual contrast effect (rather than a mere increase in statistical precision) results from presenting more than one intensity value to each S. Hull's dynamism postulate fails to predict the Grice and Hunter data, as it assumes that the excitatory strength of a stimulus is constant and based on its absolute intensity. A more adequate explanation is provided by Helson's (1964) adaptationlevel (AL) theory. Assuming that the excitatory strength of a stimulus depends on its departure from AL intensity, substantial intensity effects are expected only wher $\mathbf{S}$ experiences more than one intensity value (within-Ss design), as departures from $\mathrm{AL}$ are possible only in that case.

The present experiment was designed to further evaluate the adaptation-level interpretation of stimulus intensity effects. Ss were first adapted to either $40 \mathrm{db}$ tones, $100 \mathrm{db}$ tones, or to silence, then given a series of reaction time (RT) trials with randomized presentations of $40,60,80$, and $100 \mathrm{db}$ auditory signals. It was assumed that the effective AL during RT trials would be near 40 or $100 \mathrm{db}$ for Ss initially adapted at those levels and near the geometric mean of the test trial intensities (70 db) for Ss adapted to silence. Thus it was expected that mean RTs at all levels of signal intensity would be fastest for the $40 \mathrm{db}$ group (as test signals were at or above $\mathrm{AL}$ ), slowest for the $100 \mathrm{db}$ group (test signals were at or below $A L$ ), and intermediate for the silence group.

\section{Method}

The Ss were 30 female undergraduates at the University of Illinois. They were assigned at random to adaptation conditions, $10 \mathrm{Ss}$ to each condition.

The stimulus on both adaptation and test trials was a 1000-cycle tone of 1.5-sec. duration, produced by a Hewlett-Packard model 200 ABR audio oscillator and presented to $S$ via earphones at $40,60,80$, or 100 $\mathrm{db}, \mathrm{SPL}$. The response consisted of pressing a conventional telegraph key. The ready signal was a 10-w light of .5-sec. duration which preceded the tone by 1,2 , or 3 sec. in irregular order on successive trials. The intertrial interval was $15 \mathrm{sec}$. Temporal parameters of stimuli were controlled by 4 Hunter timers, connected in sequence. RT was recorded in milliseconds by a Hunter model 120A electronic counter.

The experiment was conducted in a soundproof room. Ss who received preliminary adaptation to 40 or $100 \mathrm{db}$ tones were given conventional reaction time instructions, then informed that $\mathrm{E}$ wished to insure that the apparatus was working and therefore, before starting the experiment, would present several tones through the earphones. Ss were requested not to press the telegraph key in response to these preliminary tones. The $\mathrm{S}$ then received 12 adaptation tones (1.5-sec. duration) at either 40 or $100 \mathrm{db}$, and at the rate of 3 per min. Ss adapted to silence sat in the soundproof room for a period of $4 \mathrm{~min}$. prior to the onset of RT trials. Following preliminary adaptation the procedure was the same for all Ss. Each $\mathrm{S}$ was given $48 \mathrm{RT}$ trials in which $40,60,80$, and $100 \mathrm{db}$ signals were presented in random order with the restriction that there be four presentations of each intensity value in each block of 16 trials.

\section{Results and Diseussion}

Figure 1 shows the signal intensity functions of the three treatment groups. It may be noted that all groups showed well-defined intensity curves, and, as predicted by AL theory, mean RT at all levels of signal intensity was fastest for Ss adapted at $40 \mathrm{db}$, slowest for Ss adapted at $100 \mathrm{db}$, and intermediate for Ss adapted to silence. The results of a 3 by 4 by 3 (adaptation procedures by signal intensities by blocks of trials) analysis of variance supported the above conclusions. The only significant sources of variation were the main effects of adaptation procedures $(F=4.66$; df 2, 27; $p<.05)$ and of signal intensity $(F=162.15$; df 3,81 ; $\mathrm{p}<.01)$. The nonsignificance of the adaptation procedures by signal intensities and adaptation procedures 


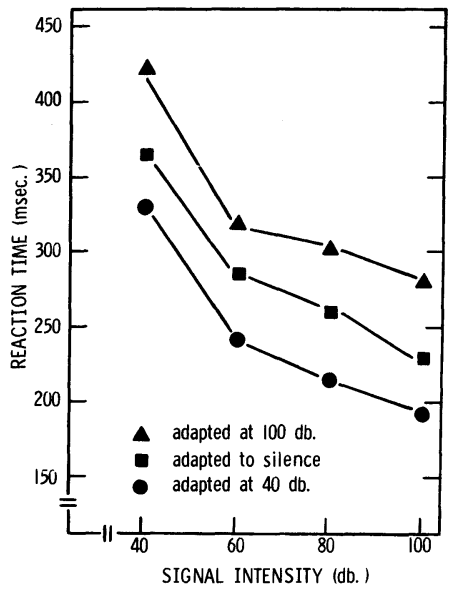

Fig. I. Stimulus intensity curves of groups adapted to $40 \mathrm{db}$. tones, $100 \mathrm{db}$. tones, and silence.

by trials interaction effects indicate respectively that stimulus intensity functions above and below AL were symmetrical, and that the AL's established by preliminary exposure to extreme stimuli remained stable during RT trials rather than shifting toward the geometric mean of the test signals. Analysis of simple effects revealed that the difference between the intensity curves of the 40 and $100 \mathrm{db}$ groups was significant $(t=3.04$; df $27 ; \mathrm{p}<.01$ ), while neither the 40 or $100 \mathrm{db}$ group differed significantly from the silence group. Finally, the difference between mean RTs of the $100 \mathrm{db}$ group to the $100 \mathrm{db}$ test signal and of the $40 \mathrm{db}$ group to the $40 \mathrm{db}$ signal was nonsignificant $(t=1.43 ;$ df $27 ; p>.20)$. This finding is consistent with AL theory as Ss under these two conditions were responding to stimuli of AL intensity, and would therefore be expected to exhibit equal responses strengths.

These findings are consistent with predictions from Helson's theory and suggest further that the excitatory strength of a stimulus depends on its departure from $\mathrm{AL}$, not its absolute intensity as assumed by Hullian theory. Another behavior-theory interpretation of stimulus intensity effects, the Logan (1954)-Perkins (1953) "constrast hypothesis," also fails to predict the present results. This formulation assumes that the net excitatory strength of a CS depends on how much generalized inhibitory potential it receives from nonreinforced background or intertrial stimuli. A more intense CS has greater excitatory strength because it contrasts more with a zero-intensity background. The LoganPerkins theory is not readily applicable to the present experiment, as overt reinforcement was not employed. However, if we assume that through transfer from previous learning the auditory signal and its absence (intertrial silence) had excitatory and inhibitory potential respectively at the start of the experiment, the theory predicts no differences among the three treatment groups. The groups did not differ with respect to degree of contrast between signal and background intensity, but performed at different levels.

\section{Referenees}

Beck, Sally B. Eyelid conditioning as a function of CS intensity, UCS intensity, and Manifest Anxiety scale score. J. exp. Psychol., 1963, 66, 429-438.

Chocholle, R. Variation des temps de réaction auditif en fonction de l'intensité à diverses fréquences. Année Psychol., 1945, 41-42, 65-124.

Gray, J. A. Relation between stimulus intensity and operant response rate as a function of discrimination training and drive. J. exp. Psychol., 1965, 69, 9-24.

Grice, G. R., \& Hunter, J. J. Stimulus intensity effects depend upon the type of experimental design. Psychol. Rev., 1964, 71, 247256.

Helson, H. Adaptation-level theory: an experimental and systematic approach to behavior. New York: Harper \& Row, 1964.

Hull, C. L. Stimulus intensity dynamism (V) and stimulus generalization. Psychol. Rev., 1949, 56, 67-76.

Logan, F. A. A note on stimulus intensity dynamism (V). Psychol. Rev., 1954, 61, 77-80.

Perkins, C. C., Jr. The relation between conditioned stimulus intensity and response strength. J. exp. Psychol., 1953, 46, 225-231.

\section{Notes}

1. This research was supported by National Institute for Health Grant MH-08033 to Dr. G. Robert Grice. Thanks are due to Dr. Grice for his valuable assistance.

2. First authorship was decided by the flip of a coin; the two authors contributed equally to the study. 